\title{
Phase separation dynamics in aqueous solutions of thermoresponsive polymers
}

\author{
V. I. Kovalchuk \\ Taras Shevchenko National University of Kyiv, 64/13, Volodymyrska Str., 01601 Kyiv, Ukraine
}

Received April 14, 2021, in final form September 7, 2021

\begin{abstract}
Phase transition kinetics of aqueous hydroxypropyl cellulose solution was studied by using turbidimetric monitoring and mathematical modelling techniques. Based on the nonlinear Cahn-Hilliard equation with a mobility depending on the component concentration, the phase separation has been modeled on a simple onedimensional Flory lattice. For value set of the interfacial energy parameter, data were obtained on the changing of the average values of the cluster sizes, their mass and concentration. The simulation results allow us to distinguish three stages of the spinodal decomposition: early, intermediate and final. It was found that for the intermediate stage, the kinetics of the cluster mass growth is described by a dependence that is characteristic of the usual diffusion mass transfer; the change in the average cluster size can be represented by a scaling function with an exponent close to $1 / 3$, typical of the systems with a conserved scalar order parameter. It is shown that the concentration of clusters at the final stage is determined by the temperature dependence of the interfacial energy.
\end{abstract}

Key words: thermoresponsive polymer, spinodal decomposition, Cahn-Hilliard equation

\section{Introduction}

Phase separation of thermoresponsive polymers - cellulose ethers - is an intensive area of researches based on promising technologies in various fields, including the food industry, personal hygiene products, medicine, pharmacology, and environmentally friendly materials [1, 2]. The kinetics of phase separation in solutions of cellulose derivatives is a rather complex process, the understanding of which is necessary to create materials with specified physicochemical properties.

Aqueous solutions of thermoresponsive polymers undergo a sol-gel transition upon heating, returning to their original state upon cooling [3, 4]. Gelation of such a system is associated with an increase of the solution turbidity resulting from phase separation. To date, the gelation mechanism is still not well understood, although many different hypotheses have been proposed ([5] and references therein). Structural and rheological properties of polymer gels based on cellulose derivatives have been intensively studied since 1935 and all the experimental data accumulated to date indicate that the mechanism of phase separation in such systems is spinodal decomposition [5-8]. Spinodal decomposition is the initial stage of phase transformation when the system was preliminarily brought to a thermodynamically unstable state. This instability at a given temperature corresponds to the section of the free energy curve where its second derivative with respect to concentration is negative. In the region of spinodal decomposition, the solution domains with an increased or decreased concentration relative to its average value - clusters - arising due to thermal fluctuations become stable and begin to grow. This process is maintained by ascending diffusion [9], when the mutual attraction of the same type of particles leads at the next time moments to an even greater increase of their concentration in the cluster and to a further depletion of the adjacent solution zone. In the case of spinodal decomposition, the separation of a substance into various phases occurs uniformly throughout the entire solution volume; therefore, the sol-gel transition in such systems is also called the volume phase transition [10, 11]. 


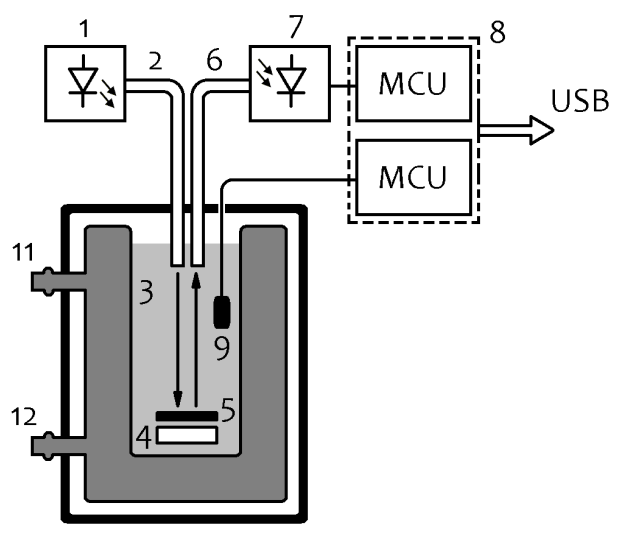

Figure 1. Installation scheme for turbidity measuring (see explanations in the text).

This paper is devoted to the study of the phase transition kinetics in aqueous solutions of thermoresponsive polymers - cellulose derivatives.

\section{Experiment}

As the object of our study we selected a $2 \mathrm{wt} \%$ aqueous solution of hydroxypropyl cellulose manufactured by Alfa Aesar [12]. For this hydroxypropyl cellulose, its molecular weight was $10^{5}$, and the substitution degree was $75.7 \%$.

Figure 1 illustrates the scheme of the experimental setup, which is an improved version of the device used in [13] for turbidity measuring.

As a light source 1, the GNL-5013PGC LED was used. It was powered by a micropower current stabilizer made on the LP2951 chip. Light beam with a wavelength of $525 \mathrm{~nm}$ was fed through the optical-fiber cable 2 into the thermostated chamber 3 filled with a polymer solution. The beam reflected from the mirror 4 was returned via the fiber cable 6 to the digital optical sensor 7 (TLS237) connected to the microcontroller 8 (AVR ATmega328P). As a result, the total intensity was measured: $J_{\Sigma}=J_{T}+J_{R}$, where $J_{T}$ is the intensity of the weakened light flux due to the passage through the sample, $J_{R}$ is the intensity of the light flux reflected (backscattered) by the sample. To measure $J_{R}$, mirror 4 was shielded by a shutter 5 made of light-absorbing material (black anodized aluminum). Thus, in order to determine $J_{T}$ and $J_{R}$ for a specific sample, it was necessary to perform two measurements: with and without screen 5 .

The solution temperature was measured by the digital temperature sensor 9 (LMT01LPG) connected to the second identical microcontroller of unit 8 . The values of luminosity and temperature were synchronously read by the unit 8 and transmitted via the RS-232 protocol into a USB ports of a PC. Data capture, their subsequent processing, and visualization were implemented by a program written in Delphi. The luminosity measurement error did not exceed 0.1 lux, and the temperature measurement accuracy was $\pm 0.1^{\circ} \mathrm{C}$. Chamber 3 was enclosed in a light-tight case 10 and was connected through outputs 11,12 to a Julabo ME-6 circulation thermostat. Structurally, elements 4, 5, 9 together with the output (input) of fiber cables 2, 6 were designed as a probe immersed in the solution to be researched.

Figure 2 shows the measurement results for the investigated polymer solution. The curve in this figure was calibrated with a turbidity level of $0 \%$, which corresponds to the illumination value of the photo sensor at a sample temperature of $25^{\circ} \mathrm{C}$.

From the analysis of the experimental curve behavior it follows that the observed turbidity can be conditionally divided into three sections, each of which is approximated by linear dependencies (straight lines $a, b$, and $c$ ). The intersection point of straight lines $a$ and $b$ corresponds to $T_{A}=38.6^{\circ} \mathrm{C}-$ the so-called cloud point [5]; the intersection point of straight lines $b$ and $c$ determines $T_{B}=40.8^{\circ} \mathrm{C}-$ the temperature of the phase transition completion. The phase transition temperature can be defined as $T_{P}=\left(T_{A}+T_{B}\right) / 2=39.7^{\circ} \mathrm{C}$. The obtained temperature is in agreement with the data of other authors: $T_{P}=39 \pm 1^{\circ} \mathrm{C}[14], T_{P}=40.3^{\circ} \mathrm{C}[15]$. 


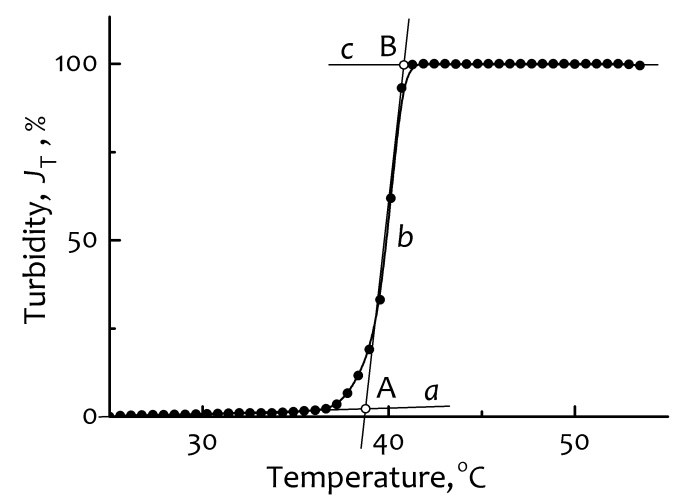

Figure 2. Turbidity as a function of temperature for the $2 \mathrm{wt} \%$ aqueous hydroxypropyl cellulose solution; the temperature was ramped from 25 to $60^{\circ} \mathrm{C}$ at a rate of $1.1^{\circ} \mathrm{C} / \mathrm{min}$. See other explanations in the text.

\section{Formalism}

When describing the features of phase formation in the region of spinodal decomposition, one of the most successful approaches is the Cahn-Hilliard model [16-18], developed on the basis of the free energy density functional method [19,20]. The Cahn-Hilliard equation does not contain any microscopic details of the described system, but includes such macroscopic characteristics as the diffusion coefficient, free and interfacial energy. The free energy density functional method makes it possible to describe in a natural way the diffusion interaction between clusters and their coagulation during the growth of a new phase without any approximations [20].

The Ginzburg-Landau type functional for the total energy of the polymer-solvent system has the form [21]

$$
\left.U[\phi]=\int \mathrm{d} \mathbf{r}\left\{F(\phi)+\kappa(\phi)|\nabla \phi|^{2}\right)\right\}, \quad \phi=\phi(\mathbf{r}, t),
$$

where $\phi$ is the order parameter which has the meaning of the polymer concentration, $F(\phi)$ is the free energy density. The second term in curly brackets under the integral sign in (3.1) describes the contribution of spatial correlation effects to free energy [9] with the gradient coefficient [22]

$$
\kappa(\phi)=\frac{a^{2}}{36 \phi(1-\phi)},
$$

where $a$ is the size of the polymer chain segments. For the Flory model, $a=1$ [23]; therefore, we omit this parameter in further notation. Let us introduce in 3.1 the dimensionless parameter $\alpha$

$$
\left.U[\phi]=\int \mathrm{d} \mathbf{r}\left\{F(\phi)+\alpha^{2} \kappa(\phi)|\nabla \phi|^{2}\right)\right\},
$$

the physical meaning of which will be clarified in the next section. For $\alpha=1$, the total energy has the form (3.1). In this work, we consider the solutions of the Cahn-Hilliard equation with $\alpha \neq 1$.

The Cahn-Hilliard equation describing the concentration evolution at a certain point in space $\mathbf{r}$ at a certain time moment $t$ has the form [21]

$$
\frac{\partial \phi}{\partial t}=\nabla\left\{M \nabla \frac{\delta U[\phi]}{\delta \phi}\right\}+\xi,
$$

where $M$ is the mobility, $\xi=\xi(\mathbf{r}, t)$ is a stochastic function (thermal noise) that satisfies the fluctuationdissipation theorem [24].

To solve equation 3.4 with functional 3.3, we use the Flory-Huggins free energy of mixing for polymer-solvent systems [23, 25]

$$
F(\phi)=N_{P}^{-1} \phi \ln \phi+(1-\phi) \ln (1-\phi)+\chi \phi(1-\phi),
$$


where $N_{P}$ is the polymerization degree, $\chi$ is the Flory-Huggins parameter describing pair interactions between monomers. Then, the total energy variational derivative with respect to $\phi$ takes the form [21]

$$
\frac{\delta U[\phi]}{\delta \phi}=f(\phi)-\alpha^{2}\left[\lambda(\phi)|\nabla \phi|^{2}+2 \kappa(\phi) \Delta \phi\right],
$$

where

$$
\begin{gathered}
f(\phi)=N_{P}^{-1}(\ln \phi+1)-\ln (1-\phi)-\chi(2 \phi-1)-1, \\
\lambda(\phi)=\frac{2 \phi-1}{36 \phi^{2}(1-\phi)^{2}} .
\end{gathered}
$$

Let us believe that the mobility of polymer molecules depends on their concentration [26]

$$
M=M_{0} \phi(1-\phi) .
$$

Thus, the Cahn-Hilliard equation takes the form

$$
\frac{\partial \phi}{\partial t}=M_{0} \nabla\left\{\phi(1-\phi) \nabla\left(f(\phi)-\alpha^{2}\left[\lambda(\phi)|\nabla \phi|^{2}+2 \kappa(\phi) \Delta \phi\right]\right)\right\}+\xi .
$$

This is a fourth-order nonlinear parabolic partial differential equation with a stochastic term. To enforce the mass conservation law and descending of total energy with time, equation 3.10) must be equipped with the homogeneous Neumann boundary conditions [19].

\section{Calculation results and discussion}

Equation 3.10 describes the temporal evolution of a conservative (potential) field, which is a continuous and sufficiently differentiable function. In [27], the solvability of the Cahn-Hilliard equation and the existence of a set of stationary states, to which the initial distributions $\phi(\mathbf{r}, 0)$ are attracted at $t \rightarrow \infty$, were proved.

Without loss of generality, let us investigate solutions of the one-dimensional equation 3.10 . Introducing a spatio-temporal grid for $x_{i} \in[1, L](i=1,2, \ldots, L)$ and $t^{n} \in[0, \infty)(n \in \mathbb{N})$ with periodic boundary conditions, we use for 3.10 the semi-implicit difference scheme proposed in [21]

$$
\phi_{i}^{n+1}=\phi_{i}^{n}+M_{0} \tau \nabla_{h}\left\{\phi_{i}^{n}\left(1-\phi_{i}^{n}\right) \nabla_{h}\left(f\left(\phi_{i}^{n}\right)-\alpha^{2}\left[\lambda\left(\phi_{i}^{n}\right)\left|\nabla_{h} \phi_{i}^{n}\right|^{2}+2 \kappa\left(\phi_{i}^{n}\right) \Delta_{h} \phi_{i}^{n+1}\right]\right)\right\}+\epsilon \nabla_{h} \eta_{i} .
$$

Here, $\tau$ is the time step, $h=1$ is the spatial step, $\nabla_{h}$ and $\Delta_{h}$ are the discrete versions of corresponding differential operators [28], $\epsilon$ is the intensity of thermal noise, $\eta_{i}$ is the sequence of standard normally distributed random variables, which is calculated once at the beginning of computations.

According to 4.1 , the transition from the $n$-th time layer to the $(n+1)$-th time layer is carried out in one step, but before that the value of $\phi_{i}^{n+1}$ in the right-hand side of equation $\sqrt{4.1}$, is found each time by the method of successive approximations from the initial $\phi_{i}^{n}$. The iterations were performed until the condition

$$
\left|\frac{\phi_{i}^{n+1}(j+1)-\phi_{i}^{n+1}(j)}{\phi_{i}^{n+1}(j)}\right| \leqslant 10^{-3}
$$

was satisfied between two successive iterations $j$ and $(j+1)$, the maximum number of iterations did not exceed 10.

The Flory-Huggins interaction parameter is $\chi=0.48$ [29] for the researched system, the initial phase was homogeneous, and the corresponding polymer concentration for a $2 \mathrm{wt} \%$ solution was $\phi_{\text {in }}=0.02 / \rho$, where $\rho=1.27 \mathrm{~g} / \mathrm{cm}^{3}$ is the density of hydroxypropyl cellulose [30]. The degree of polymerization was chosen equal to $N_{P}=300$, the values of the other parameters were: $M_{0}=0.3, \epsilon=10^{-5}$, and $\tau=10^{-5}$ (these optimal values are chosen exclusively for convenience reasons: maximum simulation time and available computing resources, since parameters specified affect only the growth rate of clusters rather 
a)

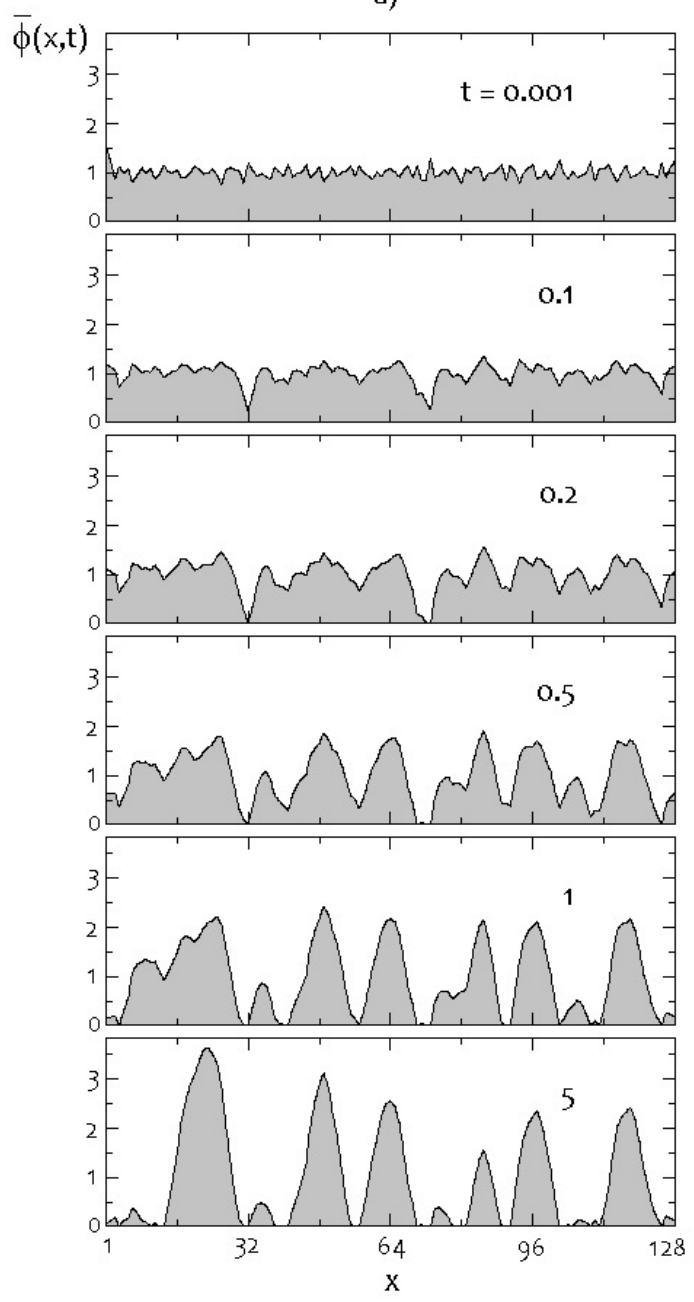

b)

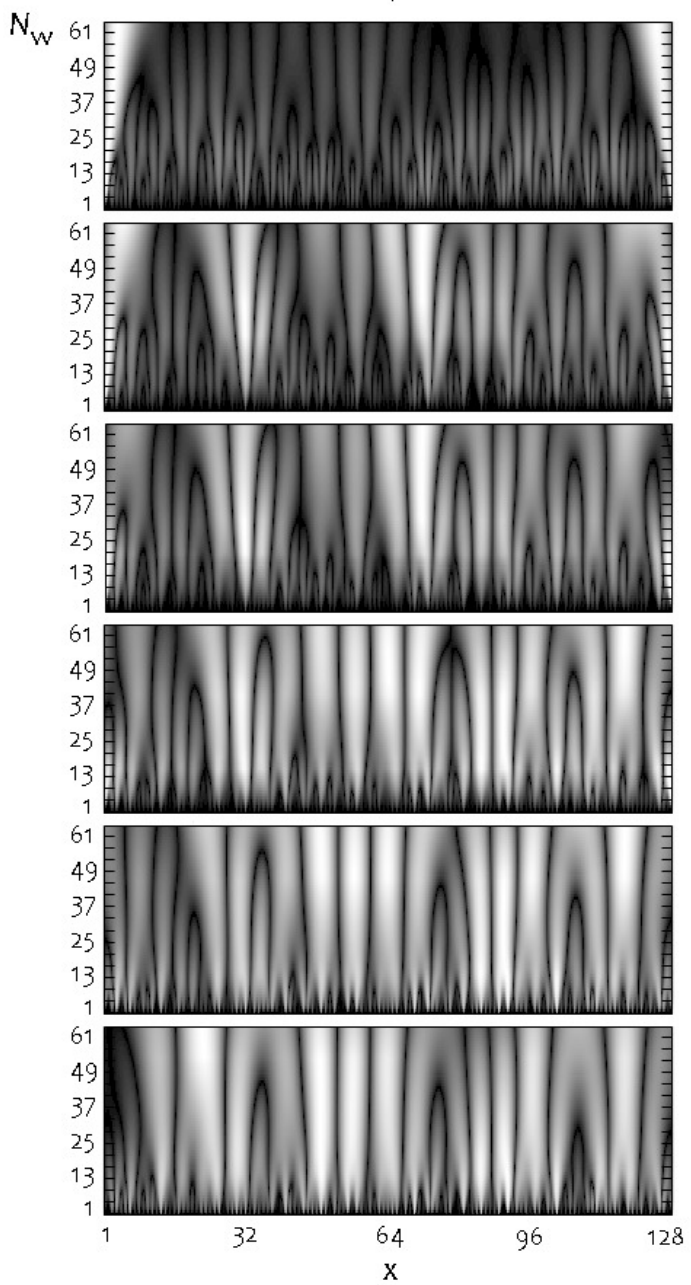

Figure 3. Distribution of the reduced concentration $\bar{\phi}(x, t)$ on a one-dimensional lattice during the spinodal decomposition in the hydroxypropyl cellulose-water system (a); the result of the wavelet transforms of the corresponding phase structures (b). The value of $\alpha$ is 0.28 .

than the microscopic features of their spatial structure). The phase structure growth was simulated on a lattice with $L=128$.

In figure $3 \mathrm{a}$, as an example, the result of numerical simulation is demonstrated for $\alpha=0.28$, where it is seen how the reduced concentration $\bar{\phi}=\phi / \phi_{\text {in }}$ changes depending on the dimensionless distance $x$ and time $t$. It can be seen how an unstable regime arises on the basis of a random distribution $(t=0.001-0.2)$, which leads to the primary structure of a new phase $(t=0.5)$, and then to its further coarsening and final formation $(t=1-5)$.

Figure 3b shows the wavelet transforms of the corresponding spatio-temporal structures presented in figure 3a; MATLAB Wave Toolbox [31] was used to construct these pictures. The numbers of the expansion coefficients using the Mexican Hat Wavelet, $N_{W}$, are shown on the vertical axis. In figure $3 \mathrm{~b}$, it can be seen that local features (non-smoothness) correspond to vertical lines going from the points where the singularities are located. The picture of the wavelet coefficients reproduces the hierarchical structure of fluctuations in the value of $\bar{\phi}(x, t)$ : for the interval $t=0.001-0.5$, one can see how the distribution of $N_{W}(x, t)$ gradually loses its fractal features - the characteristic branching inherent to local extrema disappears over time.

Note that the self-organization process of the phase structure, modeled here by the Cahn-Hilliard 


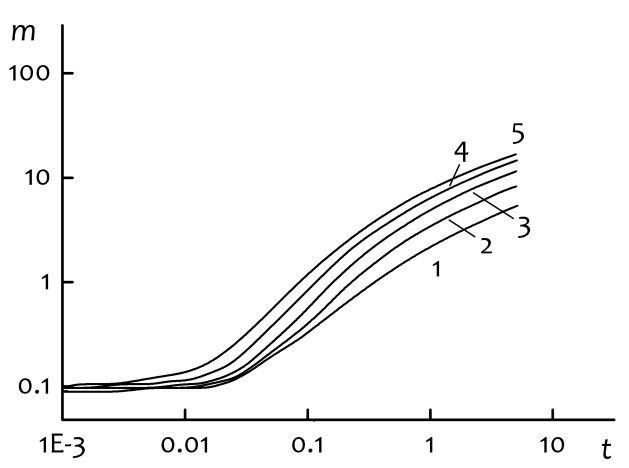

Figure 4. Dependencies of the average cluster mass over time for the set of $\alpha$ values: 0.12 (1), 0.16 (2), 0.2 (3), 0.24 (4), 0.28 (5). Averaging was performed for 100 runs of the program simulating the phase structure.

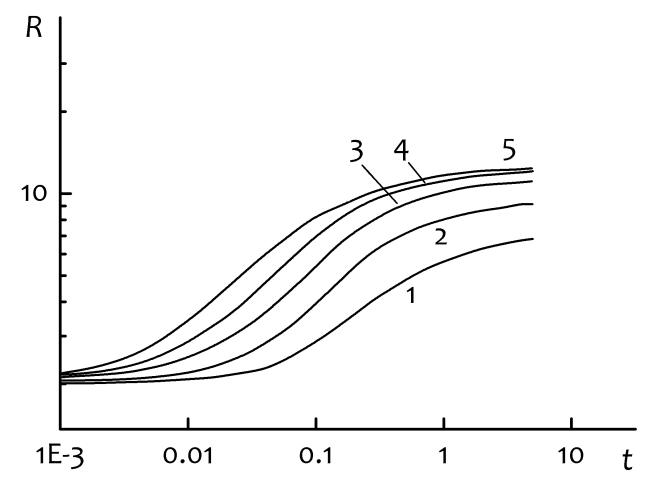

Figure 5. The same as in figure 4 but for the average cluster radius.

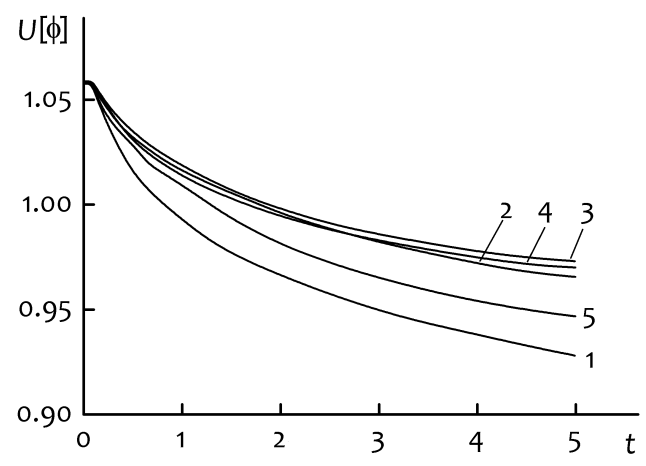

Figure 6. The same as in figure 4 but for the total energy.

equation, is provided exclusively due to diffusion mass transfer, while other mechanisms are also possible, for example, mass transfer due to interfacial tension [32]. The mechanism of internal mass transfer governing the evolution of $\bar{\phi}(x, t)$ is confirmed by an analysis of the calculation results shown in figure 4 This figure shows the time dependencies of the average cluster mass $m(t)=\left\langle S / N_{c}\right\rangle$, where $S$ is the area of the phase structure formed at the moment $t$ above level $\bar{\phi}=1$, and $N_{c}$ is the number of clusters at the level $\bar{\phi}=1$. The kinetics of mass changing was analyzed using the power function $m(t) \sim t^{\gamma}$ : approximating the results in figure 4 by linear dependencies in the range $t=0.5-5$, and we get $\gamma=0.545 \pm 0.179$. This value of $\gamma$, close to $1 / 2$, corresponds to the square root law for diffusion mass transfer [33].

Another characteristic of the asymptotic behavior of the system at large times is dynamic scaling which is determined by the characteristic length $L(t)$ of separate ordered regions of the phase structure [34]. 


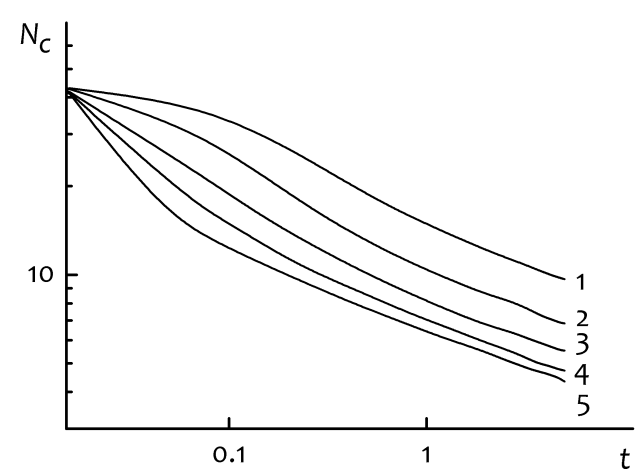

Figure 7. The same as in figure 4, but for the average number of clusters $N_{c}$.

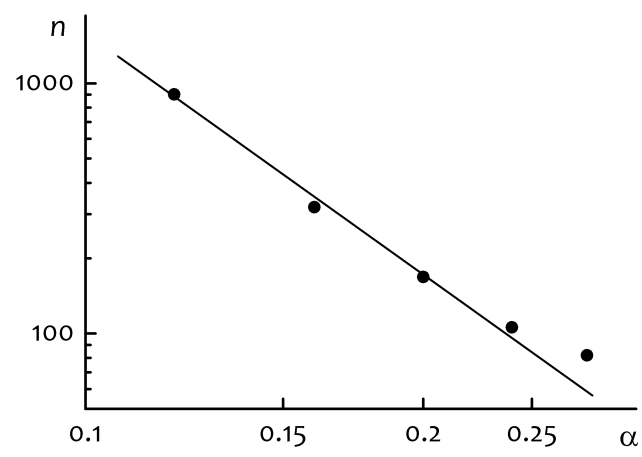

Figure 8. Volume concentration of clusters $n$ as a function of parameter $\alpha$. Simulation time is $t=5$.

Choosing the average radius of cluster $R(t)$ as characteristic length at the level $\bar{\phi}=1$, we find the scaling exponent for the growth law $R(t) \sim t^{\delta}$. The analysis of the time dependencies $R(t)$ in their longest linear sections in figure 5 gives the value $\delta=0.307 \pm 0.139$. This value is close to the exponent $\delta=1 / 3$ which is typical of the laws of growth in systems with a conserved scalar order parameter [35, 36].

The growth of the phase structure during spinodal decomposition occurs, on the whole, due to the coagulation of clusters (as can be seen from figure 3 a), while the system relaxes into an energetically more favorable state with a lower energy $U[\phi]$ (figure 6).

The descent in the total energy over time, as follows from 3.3 , occurs not only due to the change in the free energy $F(\phi)$, but also because of a decrease in the second term under the integral sign in 3.3 , which has a simple physical meaning. Cahn and Hilliard [16] showed that

$$
\int \mathrm{d} \mathbf{r} \kappa(\phi)|\nabla \phi|^{2}=\sigma / 2
$$

where $\sigma$ is the density of interfacial energy at equilibrium. During relaxation, the system tends to take a more energetically favorable state, reducing the total surface area of the clusters due to their coagulation. As a result, the interfacial energy decreases. Consequently, the $\alpha$ parameter in (3.3) determines the contribution of the interfacial energy to the total energy; besides, $\alpha$ can also depend on temperature [37, 38] like the mobility $M_{0}$ or the Flory-Huggins parameter $\chi$. In the calculations, it was found that these three parameters mainly determine the phase transition dynamics, but if $M_{0}$ and $\chi$ affect only the growth rate of new phase, then $\alpha$ determines the number of clusters in the final stage of spinodal decomposition (figure 7).

In other words, if the density of interfacial energy depends on the temperature $T$, then the number of clusters also depends on $T$. It is possible to establish the form of the phenomenological dependence $\alpha(T)$ based on the following considerations.

The result shown in figure 7 was obtained for one-dimensional case. Assuming that the solution turbidity $J_{T}$ is proportional to the volume concentration of clusters $n=N_{c}^{3}$ [39], we approximate the dependence 
of $n(\alpha)$ for the formed phase structure (at $t=5)$ by the scaling function $n \sim \alpha^{v}$ with $v=-(3.203 \pm 0.011)$ (figure 8).

In the phase transition region, turbidity is proportional to temperature (section $\mathrm{AB}$ in figure 2 ) or $J_{T} \sim \alpha^{v} \sim T$, whence $\alpha \sim T^{-0.312}$, i.e., the contribution of the interfacial energy into the total energy decreases when temperature rises.

\section{Conclusion}

In the present study, the dynamic behavior of the phase separation in aqueous solution of hydroxypropyl cellulose was analyzed by turbidimetry and mathematical modelling methods. Using the nonlinear Cahn-Hilliard equation with mobility depending on the component concentration, the phase separation was simulated on a simple one-dimensional lattice. For different values of the interfacial energy parameter, the time dependencies of the average values of cluster sizes, their mass, and concentration per unit volume were obtained. The simulation results allow us to distinguish three stages of the spinodal decomposition: early, intermediate, and final. For the intermediate stage, the kinetics of the change in the average cluster mass is described by the dependence $m(t) \sim t^{\gamma}, \gamma=0.545 \pm 0.179$, which corresponds to the square root law typical of the usual diffusion mass transfer. The growth of the average size of the phase structure elements can be described by the scaling function $R(t) \sim t^{\delta}$ with the exponent $\delta=0.307 \pm 0.139$; this value is close to $1 / 3$ that is characteristic of the systems with a conserved scalar order parameter. For the final stage, the concentration of clusters is determined by the contribution of the interfacial energy into the total energy of the system; this contribution is described by the temperature dependence $\alpha(T) \sim T^{-0.312}$

\section{Acknowledgements}

This work was supported by the Ministry of Education and Science of Ukraine by the grant "Fractal dimension and properties of liquid systems relevant for medicine and nuclear technologies" (project No. 0120U102176).

All the simulations for this work were performed using the computing cluster of the Taras Shevchenko National University of Kyiv [40].

\section{References}

1. Anastas P. T., Warner J. C., Green Chemistry: Theory and Practice, Oxford University Press, New York, 1998.

2. Kamide K., Cellulose and Cellulose Derivatives, Elsevier Science, Amsterdam, 2005.

3. Garate H., Li K.-Wo, Bouyer D., Guenoun P., Soft Matter, 2017, 13, 7161-7171, doi 10.1039/c7sm01501a

4. Lodge T. P., Maxwell A. L., Lott J. R., Schmidt P. W., McAllister J. W., Morozova S., Bates F. S., Li Y., Sammler R. L., Biomacromolecules, 2018, 19, No. 3, 816-824, doi:10.1021/acs.biomac.7b01611

5. Fairclough J. P. A., Yu H., Kelly O., Ryan A. J., Sammler R. L., Radler M., Langmuir, 2012, 28, 10551-10557, doi:10.1021/la300971r

6. Sarkar N., J. Appl. Polym. Sci., 1979, 24, 1073-1087, doi 10.1002/app.1979.070240420

7. Takeshita H., Saito K., Miya M., Takenaka K., Shiomi T., J. Polym. Sci. B., 2010, 48, 168-174, doi $10.1002 /$ polb.21885

8. Villetti M. A., Soldi V., Rochas C., Borsali R., Macromol. Chem. Phys., 2011, 212, 1063-1071, doi $10.1002 /$ macp.201000697

9. Skripov V. P., Skripov A. V., Sov. Phys. Usp., 1979, 22, 389-410, doi 10.1070/PU1979v022n06ABEH005571.

10. Weißenborn E., Braunschweig B., Soft Matter, 2019, 15, 2876-2883, doi:10.1039/c9sm00093c

11. Xia X., Tang S., Lu X., Hu Z., Macromolecules, 2003, 36, 3695-3698, doi $10.1021 / \mathrm{ma} 0216728$.

12. Hydroxypropyl Cellulose, URL https://www.alfa.com/en/catalog/043400/

13. Alekseev O. M., Zabashta Yu. F., Kovalchuk V. I., Lazarenko M. M., Bulavin L. A., Ukr. J. Phys., 2019, 64, No. 3, 238-244, doi $10.15407 /$ ujpe64.3.238

14. Desai D., Rinaldi F., Kothari S., Paruchuri S., Li D., Lai M., Fung S., Both D., Int. J. Pharm., 2006, 308, 40-45, doi $10.1016 / j$.jpharm.2005.10.011 
15. Khumana P., Singh W. B. K., Devi S. D., Naorem H., J. Macromol. Sci. A., 2014, 51, 924-930, doi $10.1080 / 10601325.2014 .953377$

16. Cahn J. W., Hilliard J. E., J. Chem. Phys., 1958, 28, 258-267, doi 10.1063/1.1744102

17. Cahn J., Acta Metall., 1961, 9, 795-801, doi 10.1016/0001-6160(61)90182-1.

18. Glotzer S. C., Paul W., Annu. Rev. Mater. Res., 2002, 32, 401-436, doi 10.1146/annurev.matsci.32.010802.112213.

19. Lee D., Huh J.-Y., Jeong D., Shin J., Yun A., Kim J., Comput. Mater. Sci., 2014, 81, 216-225, doi $10.1016 /$ j.commatsci.2013.08.027

20. L'vov P. E., Svetukhin V. V., Phys. Solid State, 2017, 59, 355-361, doi $10.1134 /$ S1063783417020160.

21. Li X., Ji G., Zhang H., J. Comput. Phys., 2015, 283, 81-97, doi:10.1016/j.jcp.2014.11.032

22. De Gennes P. G., J. Chem. Phys., 1980, 72, 4756-4763, doi 10.1063/1.439809

23. Flory P. J., Principles of Polymer Chemistry, Cornell University Press, New York, 1953.

24. Landau L. D., Lifshits E. M., Statistical Physics, Course of Theoretical Physics, Vol. 5, Elsevier, 3 edn., 2013.

25. Huggins M. L., Physical Chemistry of High Polymers, Literary Licensing LLC, 2013.

26. Dolinnyi A. I., Polym. Sci. A., 1994, 36, No. 5, 801-821 (in Russian).

27. Chafee N., Infante E. F., J. Appl. Anal., 1974, 4, 17-37, doi:10.1080/00036817408839081

28. Samarskii A. A., The Theory of Difference Schemes, CRC Press, New York, 2001.

29. Polymer-Solvent Interaction Parameter at Infinite Dilution (Flory-Huggins), URL http://polymerdatabase.com/polymer\%20physics/Chi\%20Table.html

30. Hydroxypropyl Cellulose 9004-64-2, URL https://www.guidechem.com/dictionary/en/9004-64-2.html

31. Wavelet Toolbox, URL https://uk.mathworks.com/help/wavelet/

32. Siggia E. D., Phys. Rev. A, 1979, 20, No. 2, 595-605, doi $10.1103 /$ PhysRevA.20.595

33. Zhukhovitsky A. A., Schwarzman L. A., Physical Chemistry, Metallurgy, Moscow, 2001 (in Russian).

34. Bray A. J., Rutenberg A. D., Phys. Rev. E, 1994, 49, R27-R30, doi 10.1103/physreve.49.r27

35. Lifshitz I. M., Slyozov V. V., J. Phys. Chem. Solids, 1961, 19, 35-50, doi:10.1016/0022-3697(61)90054-3

36. Bray A. J., Phys. Rev. E, 1993, 47, 3191-3195, doi 10.1103/PhysRevE.47.3191

37. Palmer S. J., Phys. Educ., 1976, 11, No. 2, 119-120, doi:10.1088/0031-9120/11/2/009

38. Lielmezs J., Herrick T. A., Chem. Eng. J., 1986, 32, 165-169, doi:10.1016/0300-9467(86)80004-1

39. Stratton J. A., Houghton H. G., Phys. Rev. 1931, 38, 159-165, doi:10.1103/PhysRev.38.159

40. High-performance computing cluster of Information and Computer Center of National Taras Shevchenko University of Kyiv, URL http://cluster.univ.kiev.ua/eng/.

\title{
Динаміка фазового розділення у водних розчинах термореактивних полімерів
}

\author{
В. І. Ковальчук \\ Київський національний університет імені Тараса Шевченка, \\ вул. Володимирська, 64/13, Київ 01601, Україна
}

\begin{abstract}
Досліджена кінетика фазового переходу у водному розчині гідроксипропілцелюлози з використанням турбідиметричного експерименту та методу математичного моделювання. На основі нелінійного рівняння Кана-Хілларда з рухливістю, що залежить від концентрації компонента, виконана симуляція розділення фаз на простій одновимірній решітці Флорі. Для набору значень параметра міжфазної енергії одержано дані про зміну у часі середніх розмірів кластерів, їх маси та концентрації. Результати моделювання дозволяють виділити три стадії спінодального розпаду: ранню, проміжну та фінальну. Встановлено, що для проміжної стадії кінетика збільшення маси кластера описується залежністю, характерною для звичайної дифузійної масопередачі; зміна середнього розміру кластера може бути представлена скейлінговою функцією з показником, близьким до 1/3, типовим для систем з консервативним скалярним параметром порядку. Показано, що концентрація кластерів на фінальній стадії визначається температурною залежністю міжфазної енергії.
\end{abstract}

Ключові слова: термореактивний полімер, спінодальний розпад, рівняння Кана-Хілларда 


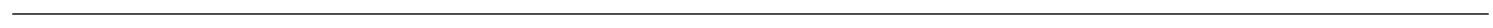

